Published by Al-Nahrain College of Medicine P-ISSN 1681-6579

E-ISSN 2224-4719

Email: iraqijms@colmed-alnahrain.edu.iq

http://www.colmed-alnahrain.edu.iq

http://www.iraqijms.net

Iraqi JMS 2018; Vol. 16(1)

\title{
Mesenchymal Cell Death in Mouse Limb Bud After the Onset of Primary Myogenesis
}

\author{
Duha M.L. Al-Musawi BSc VMS, Hayder J. Mubarak ${ }^{1}$ PhD \\ ${ }^{1}$ Dept. of Human Anatomy, College of Medicine, Al-Nahrain University, Baghdad, Iraq
}

\begin{abstract}
Background
\end{abstract}

The vertebrate limb bud develops as an outgrowth of mesoderm, which forms all their elements (muscles, nerves, vessels, bone, cartilage, and tendon). Myogenic precursor cells are seen at E11.5 mouse embryo, when the first nerve fascicles begin to enter the limb. The first signs of musculature masses are seen at E12.5 in both fore and hind limb buds. Apoptosis or programmed cell death is essential in the development of the limbs. In vertebrate, the developing limb morphogenesis depends on the appropriate spatial and temporal balance between cell death and cell proliferation.

\section{Objective} To perform comprehensive analysis of the proximo-distal pattern of cell death, evaluated by (TUNEL test) in cross sections of mouse limbs during prenatal development after onset of primary myogenesis.

Methods

Fifteen pregnant female mice (Musmusculus) were divided into three groups according to the days of pregnancy into day (14, 16 and 19), only two embryos were taken from each mouse. All the limb buds were involved in this study. Paraffin embedded histological cross-sections of the limb buds were prepared, histological staining (using H\&E stain) and TUNEL test labeling were done. Assessment of the number of apoptotic cells in the limb bud mesenchyme was done by counting these cells.

Results

The H\&E stained sections of the limb buds showed less amounts of mesenchymal tissues in older embryos (day 19). The TUNEL stain showed active apoptotic changes at proximal parts of the limb buds at gestational day 19, while the distal parts of the limbs buds showed active apoptotic changes at the early days (day 14). The evaluation of TUNEL test reaction in the proximal regions showed statistical significant increase of apoptotic cells in day 19 compared to day 14 ( $p=0.001$ for both). The mean number of apoptotic cells in the proximal regions were statistically significant $(p=0.001)$ between day 16 and day 19 . While the mean number of apoptotic cells of distal regions of the limb buds was higher at day 14 compared to that of day 16 and day 19. These differences between day 14 and day 16 were statistically significant and between day 16 and day 19 while statistically non-significant between day 14 and day 19. Comparison of mean number of apoptotic cells between proximal and distal regions in all the three groups showed a statistically significant higher mean number of apoptotic cells in the distal regions compared to proximal region $(p=0.001)$. The mean number of the apoptotic cells in both regions (proximal and distal) of the limb buds revealed statistically significant differences between day 16 and day $19(p=0.001)$.

Conclusion Apoptosis was higher in all parts of the developing limbs during day 19, and that could be associated with degenerative changes occurring at the apical ectodermal ridge. Moreover, apoptosis was higher in the distal part of the limb bud and this may be due to more differentiation of the distal parts than in the proximal part of the limb bud.

\section{Keywords Citation} Development, limb bud, mouse, embryo, TUNEL, apoptosis, mesenchyme

Al-Musawi DML, Mubarak HJ. Mesenchymal Cell death in mouse limb bud after the onset of primary myogenesis. Iraqi JMS. 2018; Vol. 16(1): 41-50. doi: 10.22578/IJMS.16.1.7

List of abbreviations: AER = Apical ectodermal ridge, H\&E = Hematoxylin and eosin

\section{Introduction}

$\mathrm{V}$ Tertebrate limbs develop from undifferentiated homogenous mesenchymal cells that are surrounded by the ectoderm (1). The limb patterning includes three spatial axes; (proximal to distal, anterior to posterior, and dorsal to ventral axes (2).

Morphogenesis of the upper and lower limbs is similar; their outer shape is formed when 
mesenchymal cells in the buds start to condense. The layer of ectoderm at the distal border of the limb is thickened to form the apical ectodermal ridge which induces limb bud formation and elongation (3).

In mouse, the first sign of the limb development recorded during the E9.5 and E10. At E11.5, the long bones of the limbs develop in proximodistal direction and by the E14.5 the most distal phalanges are formed ${ }^{(4)}$.

The limb buds develop as an outgrowth of mesoderm which form all their elements (muscles, nerves, vessels, bone, cartilage, and tendon) with a supervision of the apical ectodermal ridge (AER), which is formed at the junction between the ventral and dorsal ectoderm ${ }^{(5)}$.

During development, the digits of limbs become separated due to interdigital apoptosis as well as differential growth of the digital tips (6).

The ossification of the limb elements shows different stages which start by the stage of precartilaginous condensations in the presumptive bones, then displaying the proliferating chondrocytes. The chondrogenic precursor cells condense in the center of the limb buds to form chondrogenesis center, in addition for tendons and muscles, which condense in the rims of bud. Myogenic precursor cells are seen at E11.5 mouse embryo, when the first nerve fascicles begin to enter the limb. The first signs of musculature masses were seen at E12.5 in both fore and hind limb buds (4).

The cell death (apoptosis) is important to balance the cell proliferation during development ${ }^{(7)}$. The apoptosis is the major cell death pathway for removing unwanted in a clean or silent manner during embryonic development ${ }^{(8)}$. Apoptosis as a programmed cell death is essential in the development of the limbs (9). The programmed cell death take place in the developing limb in areas of the undifferentiated mesoderm in connection with the establishment of the pre-chondrogenic condensations of the skeleton, in addition cell death is also observed during the formation of the joints (10). The areas of apoptosis are recoded with the formation of the shape and skeleton of the limb, it shows a significance difference between species members ${ }^{(11)}$.

The (TUNEL) is a detecting technology for DNA fragmentation by labeling the terminal end of nucleic acids. It uses to recognize DNA fragmentation of apoptotic signaling cascades (12). The DNA fragmentation might occur after the release of enzymes from cytoplasmic membrane ${ }^{(13)}$.

This study had been done to perform comprehensive analysis of the proximodistal pattern of cell death evaluated by (TUNEL test) in cross sections of mouse limbs during prenatal development after onset of primary myogensis.

\section{Methods}

Fifteen pregnant female mice (Musmusculus), aged about 10-12 weeks, weighing between 25-30 g, were divided into three group according to the days of pregnancy into day $(14,16$ and 19$)$, only two embryos were taken randomly from each mouse. All the limb buds were involved in this study (Table1).

Limb buds were separated according to their age in containers in order to be fixed with formalin $10 \%$, followed by fixation, dehydration, clearing, paraffin embedding and sectioning dewaxing and hydration were done 14. Serial sections of 5-6 $\mu \mathrm{m}$ thickness were cut using the electrical microtome.

The TUNEL-based detection kit was provided by abcam $^{\circledR}$ with kit code ab66108. The fluorescin-labeled DNA was observed with a fluorescent microscope.

Statistical evaluation of the number of apoptotic cells in the limb bud mesenchyme that were showed in a bright yellow fluorescent color was done depending on the counting these cells. 
Iraqi JMS 2018; Vol. 16(1)

Table 1. Arrangement of Samples groups according to the days of Pregnancy

\begin{tabular}{cccc}
\hline Days of pregnancy & $\begin{array}{c}\text { No. of female mice in } \\
\text { each day }\end{array}$ & $\begin{array}{c}\text { No. of embryos that } \\
\text { were taken } \\
\text { randomly }\end{array}$ & $\begin{array}{c}\text { No. of limb bud that } \\
\text { were taken from } \\
\text { embryo }\end{array}$ \\
\hline 14 & 5 & 10 & 40 \\
16 & 5 & 10 & 40 \\
19 & 5 & 10 & 40 \\
\hline Total & 15 & 30 & 120 \\
\hline
\end{tabular}

\section{Results}

The TUNEL test of the limb buds at the variable stages of development showed three different fluorescent colors:

- Yellow color representing the apoptotic cells (positive color).

- Orange color for the non-apoptotic cells (negative color).

- Green color, also a negative color.

The Abcam's in situ Direct DNA Fragmentation Assay Kit used provided two components including positive and negative control cells for conveniently detecting DNA fragmentation by fluorescence microscopy.

The TUNEL test applied in this study showed evaluation of apoptosis ratio in the limb buds.

The variable regions of mesenchymal tissue of the proximal and distal limb bud were evaluated by counting the number of the cells undergo apoptosis. The counting of the positive fluorescent cells in the mesenchymal tissue of the limb buds illustrated the bright yellow colored apoptotic cells (Figures 1, 2, 3, 4).

Evaluations of apoptotic cells in proximal regions of limb bud

Day 14 and Day 16

The counting of the fluorescent cells in the proximal regions of limb bud showed a mean value at day 14 was $(90.1 \pm 2.7)$. While that at day 16 was (95.0 \pm 4.7 ) (Table 2); t-test revealed a non-significant difference between the mean value in the proximal regions at day 14 and day 16.

\section{Day 16 and Day 19}

The mean value in proximal regions of limb buds at day 16 was $(95.0 \pm 4.7)$. While that at day 19 was $(180.0 \pm 8.3)$ (Table 3); t-test revealed significant higher values of apoptotic cell in day 19 compared to day 16 ( $p \leq 0.05)$.

\section{Day 14 and Day 19}

The mean value of apoptotic cell in proximal regions of limb bud at day 14 was $(90.1 \pm 2.7)$. While that at day 19 was (180.0 \pm 8.3$)$ (Table 4); t-test revealed a significant increase of apoptotic cell in day 19 compared to day 14 $(p \leq 0.05)$.

\section{Evaluations of apoptotic cells in distal regions} of limb buds

\section{Day 14 and Day 16}

The mean value of apoptotic cell in distal regions at day 14 was $(279.0 \pm 10.07)$. While that at day16 was $(203.0 \pm 10.56)$ (Table 5); ttest revealed a significant increase of apoptotic cell in day 14 compared to day 16 ( $p \leq 0.05)$.

\section{Day 16 and Day 19:}

The mean value of apoptotic cell in distal regions at day 16 was (203.0 \pm 10.56$)$. While that at day 19 was $(257.0 \pm 14.06)$ (Table 6); ttest showed a significant increase of apoptotic cells in day 19 compared to day16 ( $p \leq 0.05)$.

\section{Day 14 and Day 19}

The mean value in distal regions at day 14 was

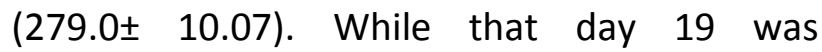
(257.0 \pm 14.06$)$ (Table 7); t-test in distal regions 
revealed a non-significant variability between the mean value at day 14 and day 19.

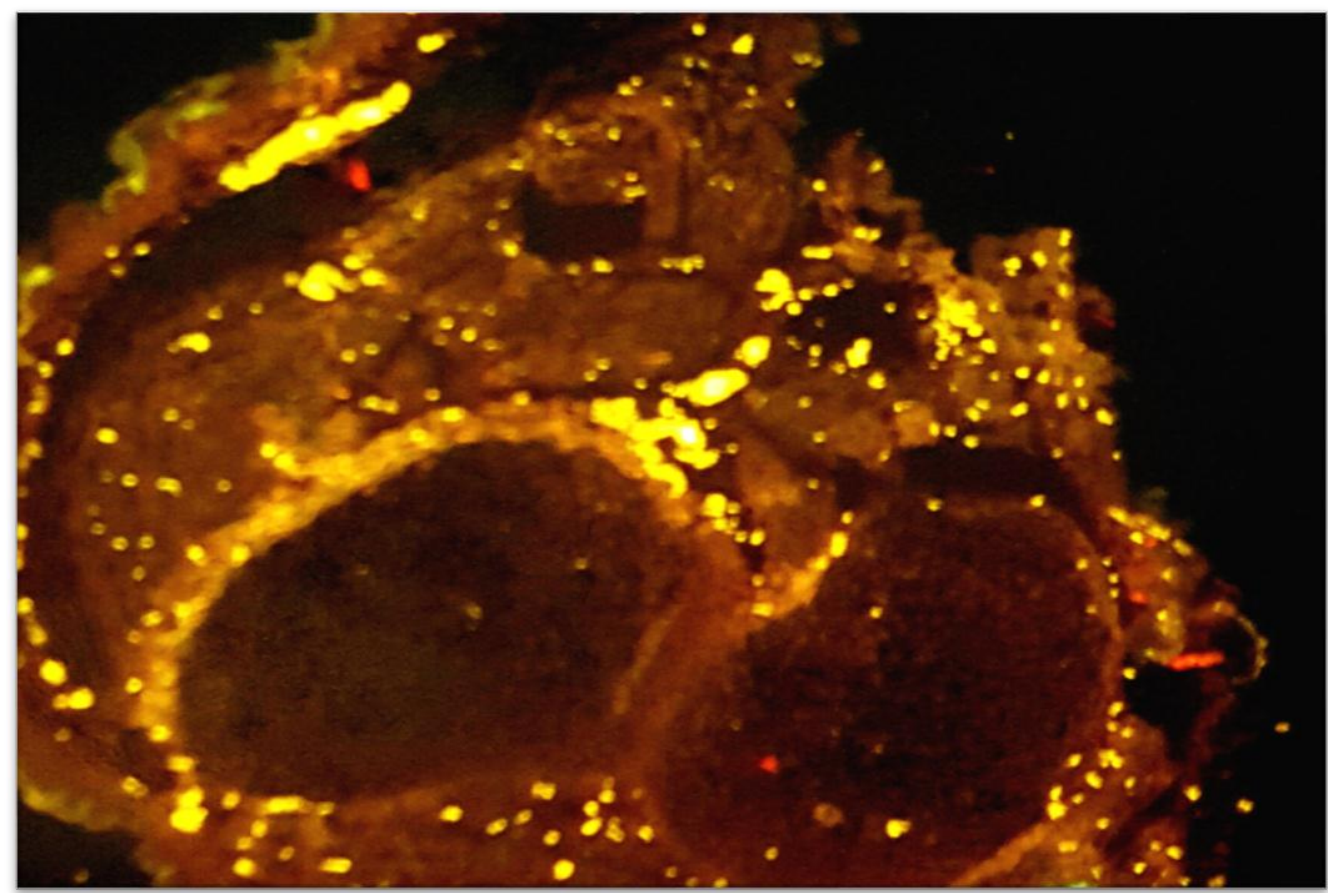

Figure 1. Cross section of the proximal regions at day 16 showing bright yellow color of apoptotic foci TUNEL test (100X)

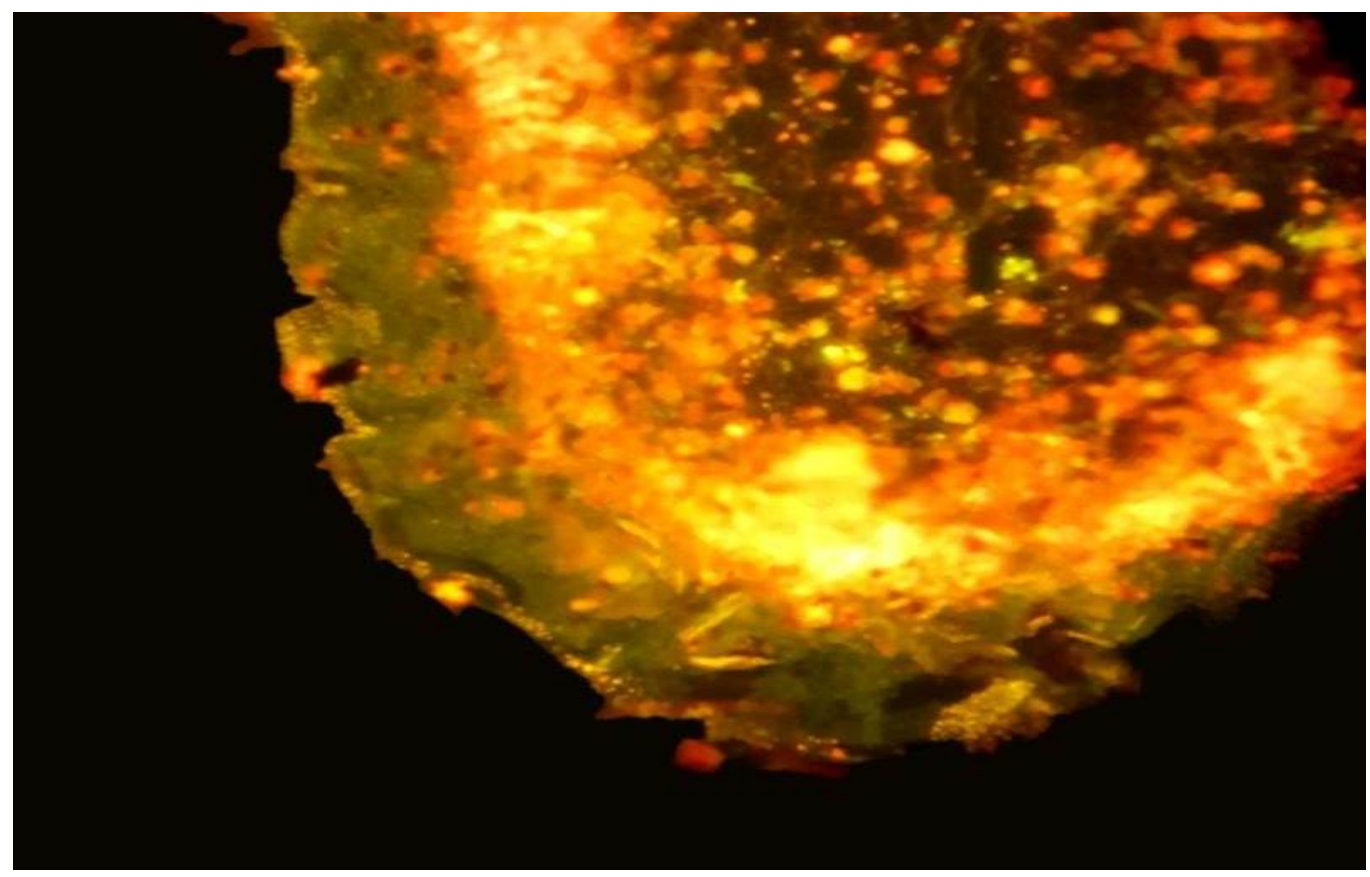

Figure 2. Cross section of the proximal regions at day 19 showing bright yellow color of apoptotic foci TUNEL test (400X) 


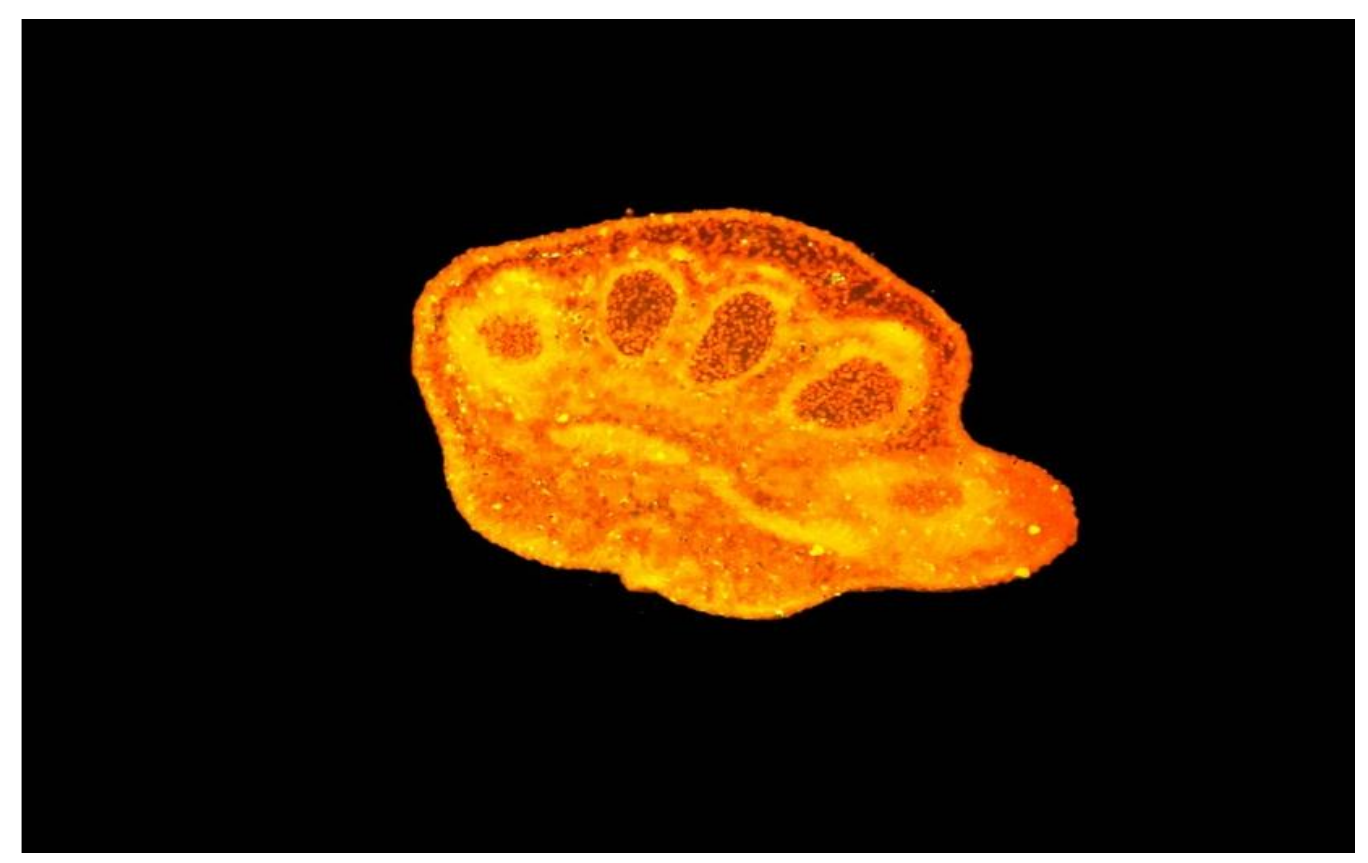

Figure 3. Cross section of the distal regions at day 14 showing bright yellow color of apoptotic foci TUNEL test (100X)

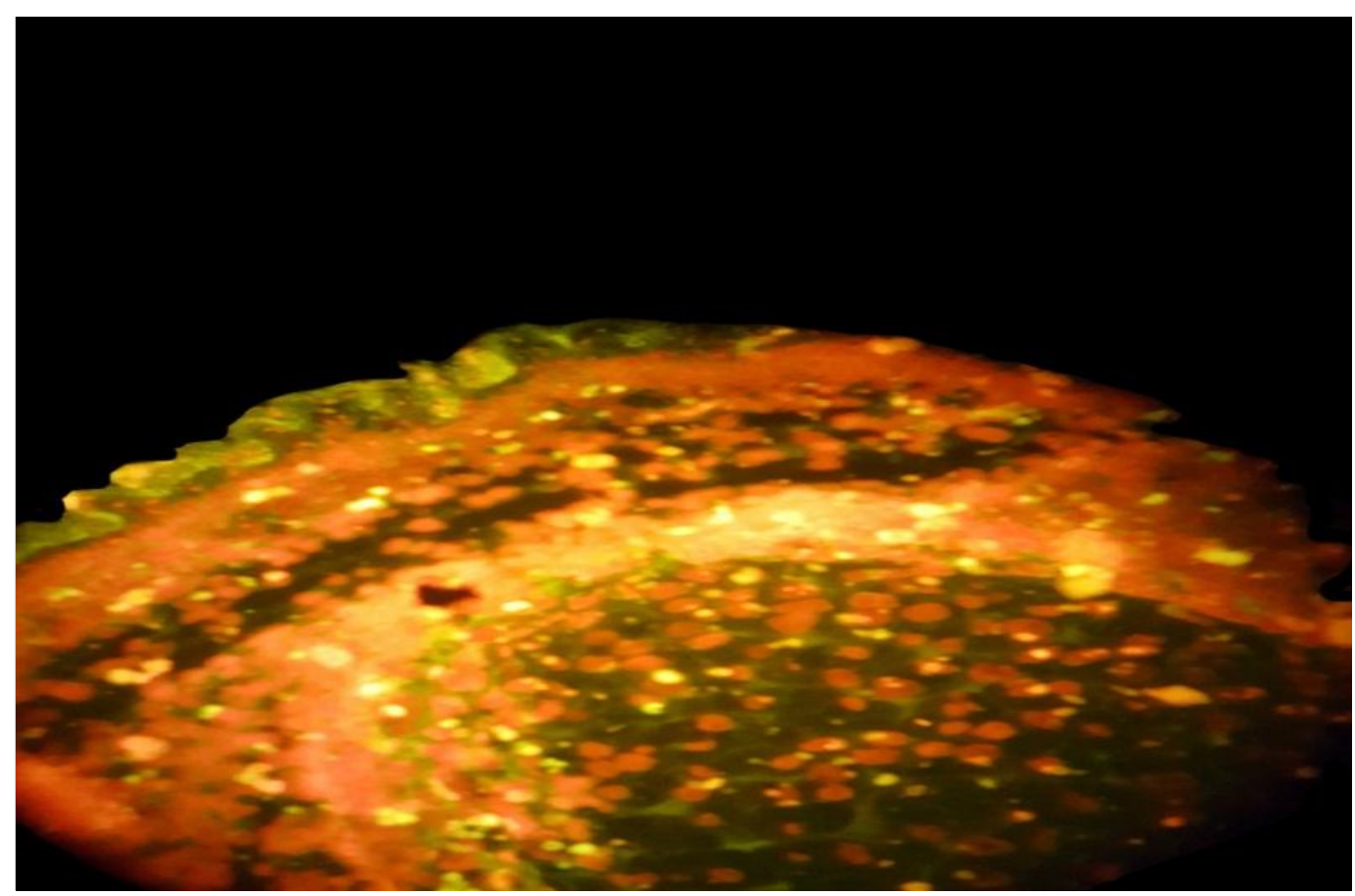

Figure 4. Cross section of the distal regions at day 16 showing bright yellow color of apoptotic foci TUNEL test (400X) 
Table 2. Mean number of apoptotic cells revealed in proximal regions in E14 and E16 by TUNEL test

\begin{tabular}{ccc}
\hline Age & Mean \pm SE & P value \\
\hline Day 14 & $90.1 \pm 2.7$ & 0.2 \\
Day 16 & $95.0 \pm 4.7$ & 0.7 \\
\hline
\end{tabular}

Table 3. Mean number of apoptotic cells revealed in proximal regions in E16 and E19 by TUNEL test

\begin{tabular}{ccc}
\hline Age & Mean \pm SE & P value \\
\hline Day 16 & $95.0 \pm 4.7$ & 0.001 \\
Day 19 & $180.0 \pm 8.3$ & \\
\hline
\end{tabular}

Table 4. Mean number of apoptotic cells revealed in proximal regions in E14 and E19 by TUNEL test

\begin{tabular}{ccc}
\hline Age & Mean \pm SE & P value \\
\hline Day 14 & $90.1 \pm 2.7$ & 0.001 \\
Day 16 & $180.0 \pm 8.3$ & \\
\hline
\end{tabular}

Table 5. Mean number of apoptotic cells revealed in distal regions in E14 and E16 by TUNEL test

\begin{tabular}{ccc}
\hline Age & Mean \pm SE & P value \\
\hline Day 14 & $279.0 \pm 10.07$ & 0.004 \\
Day 16 & $203.0 \pm 10.56$ & \\
\hline
\end{tabular}

Table 6. Mean number of apoptotic cells revealed in distal regions in E16 and E19 by TUNEL test

\begin{tabular}{ccc}
\hline Age & Mean \pm SE & P value \\
\hline Day 16 & $203.0 \pm 10.56$ & 0.004 \\
Day 19 & $257.0 \pm 14.06$ & 0 \\
\hline
\end{tabular}

Table 7. Mean number of apoptotic cells revealed in distal regions in E14 and E16 by TUNEL test

\begin{tabular}{ccc}
\hline Age & Mean \pm SE & P value \\
\hline Day 14 & $279.0 \pm 10.07$ & 0.2 \\
Day 19 & $257.0 \pm 14.06$ & \\
\hline
\end{tabular}


Comparison of mean number of apoptotic cells between proximal and distal limb bud

The mean value of apoptotic cell in proximal regions at days E14, E16 and E19 were (180.0 \pm 16.5 ). While that in distal region at days E14,
E16 and E19 were (246.3 \pm 7.83$)$ (Table 8). T-test showed significantly higher mean values of the apoptotic cells in the distal regions compared to proximal region ( $p \leq 0.05)$.

Table 8. Mean number of apoptotic cells revealed in proximal regions and distal regions by TUNEL Test

\begin{tabular}{ccc}
\hline Region & Mean \pm SE & P value \\
\hline Proximal & $121.7 \pm 6.5$ & 0.001 \\
Distal & $246.3 \pm 7.83$ & \\
\hline
\end{tabular}

The mean number of apoptotic cells in both regions of limb buds

Day 14 and Day 16

The mean value of apoptotic cells at day 16 was $(149.0 \pm 15.3)$. While that at day E14 was (184.5 \pm 15.9$)$ (Table 9); t-test showed a nonsignificant variability was in the mean value of the counted cells during day 14 and 16 .

\section{Day 19 and Day 16}

The mean value of apoptotic cells at day 19 was (305.5 \pm 11.8$)$. While that at day 16 was
(149.0 \pm 15.3$) \quad$ (Table 10); t-test showed significantly higher mean values of the apoptotic cells in the day 19 compared to day 16 ( $p \leq 0.05)$.

\section{Day 14 and Day 19}

The mean value of apoptotic cells at day 19 was (305.5 \pm 11.8$)$. While that at day 14 was (184.5 \pm 15.9$)$ (Table 11); t-test revealed a significant value of apoptotic cell which was higher in day 19 compared to day $14,(p \leq$ 0.05).

Table 9. Mean number of apoptotic cells revealed in both regions at E14 and E16 by TUNEL test

\begin{tabular}{ccc}
\hline Age & Mean \pm SE & P value \\
\hline Day 14 & $184.5 \pm 15.9$ & 0.2 \\
Day 16 & $149.0 \pm 15.3$ & 0.2 \\
\hline
\end{tabular}

Table 10. Mean number of apoptotic cells revealed in both regions at E16 and E19 by TUNEL test

\begin{tabular}{ccc}
\hline Age & Mean \pm SE & P value \\
\hline Day 16 & $149.0 \pm 15.3$ & 0.001 \\
Day 19 & $218.5 \pm 11.8$ & 0 \\
\hline
\end{tabular}


Table 11. Mean number of apoptotic cells revealed in both regions at E14 and E19 by TUNEL test

\begin{tabular}{ccc}
\hline Age & Mean \pm SE & P value \\
\hline Day 14 & $184.5 \pm 15.9$ & 0.001 \\
Day 19 & $218.5 \pm 11.8$ & \\
\hline
\end{tabular}

\section{Discussion}

It was reported that the developing vertebrate limb morphogenesis depends on the appropriate spatial and temporal balance between cell death and cell proliferation ${ }^{(15)}$.

The results of this study indicate that the proximal parts of the limb bud are more actively involved with apoptotic changes at gestational day 19. The pattern of apoptosis in the proximal parts of the limb buds at the earlier developmental stages was found to be steady. The distal parts of the limbs showed active apoptotic changes at the earlies day 14 .

The myogenic differentiation was reported to be associated with cell death to eliminate excess cells around the developing muscles (16). However, the evaluation of proximodistal sequential localization of the phenomenon of apoptosis was not described.

The localization of cell death along the arthogonal axes in relation with the organization of the skeletal pattern of the limb described in this study was also reported in a study on early avian limb, the avian limbs showed regional variability with an anterior and posterior areas of cell death (11).

The results of this study do not agree with Milaire and Roze in $1983^{(17)}$ who mention that no regional variability in different zones of early developing limb of mammals. This disagreement could be related to the more accurate enlightenment of apoptosis by TUNEL technique used in this study, or it may be related the different chronological development of the limb bud as this study evaluate more later developmental stages.

The more massive apoptosis in the distal regions found in this study during the gestational day 14 was supported by the Hurle et al in 1996 (18) who reported massive programed cell death at the distal mesoderm that serve in phenotyping of digits.

Many physiological triggering signals for apoptosis were reported in the developing limb buds including the expression of BMP-2, BMP-4 and BMP-7 (19).

Also, previous studies support the coexistence of different cell death effectors in association with apoptosis of the mesodermal tissues of the developing limb buds (20-22).

The evaluation of the programmed cell death in both the upper and lower limbs buds was based on the assumption reported in the literatures that apoptosis in the upper and the lower limb buds provides a valuable model that mold the limb bud tissues to present the morphological and functional specialization in different vertebrated including ducks, turtles, bats, chickens, humans, and lizards ${ }^{(23,24)}$.

The programmed cell death detected by the TUNEL stain in this study after the onset of primary myogenesis after day 14 was higher in all parts of the developing limbs during day (19). This result is supportive to the finding of, casps- 3 and -9 began was found to be detected from 13.5 gestational day and become more strengthened during the later period of embryogenesis suggesting that the Casp family starts to be expressed in accordance with onset of myogenesis ${ }^{(25)}$.

It was concluded that signaling (as fibroblast growth factor) from the most distal part of the limb buds (the apical ectodermal ridge) at different developmental stages regulates cellular growth located at the most proximal parts. This signaling was essential to ensure normal skeletal elements, and perhaps other limb tissues ${ }^{(26)}$. Also, it was reported that the mesenchymal region underlying the distal ectoderm was found to show massive cell death after removal of the apical ectodermal 
ridge $(27,28)$. This finding is supportive to the results of this study, the later stage involved in this study (day 19) is associated with degenerative changed of the apical ectodermal ridge (29) and this may the underlying factor leading to massive cell death at this developmental stage as cell death might be due to an indirect effect of loss of signaling associated with absence of the apical ectodermal ridge in later developmental stages.

The results of this study evaluated the reactivity of TUNEL test labeling apoptotic cell in mesenchymal tissues seen in the transverse sections of limb around the various tissue components. This approach was established after the reports that ensure uncertainty whether the labeling of dying cells could be a progenitor of chondrocytes or other cell types in the limb ${ }^{(30)}$.

The higher apoptotic activity at the distal regions of the developing limb was determined in all the three developmental stages involved in this study. This result was in agreement with the with previously suggested limb patterning of the progress zone model ${ }^{(31)}$, which had been the most important model of limb proximaldistal patterning since decades. This model postulated that limb progenitors in a 'progress zone' in the limb bud distal tip become progressively 'distalized'. As cells proliferate but progress zone size remains constant, cells must be continually exiting the progress zone. Once they leave, they cease distalizing. Therefore, cells exiting early form proximal skeletal elements whereas those exiting late form distal elements. Signaling from the apical ectodermal ridge was thought to be the accommodating factors that allow progress zone cells to continue distalizing. Therefore, the proximal regions of the limb buds showing active apoptosis in this study as a phenomenon associated with early maturation of the proximal musculoskeletal elements, the late distal increase of labeled apoptotic cells found in this study is related to maturation of the distal musculoskeletal elements of the limbs.
This interpretation was supported by the establishment reported previously that distal region is specified only after proximal (32).

The methodology of t-test statistical analysis has been used in this study to compare variables associated with the subsequent chronology of mesenchymal cell apoptosis, this scheme of statistical analysis provides simplicity of interpretation and ease for calculation in the manner that inaugurate with the aims of the study (33).

This study concluded that the active apoptosis during myogenesis showed proximodistal pattern regulating limb morphogenesis.

\section{Acknowledgments}

Regard and gratefulness should be presented to the staff members Department of Human Anatomy at the College of Medicine Al-Nahrain University for their assistance and cooperation.

\section{Authors Contribution:}

Al-Musawi: Performing the laboratory research work. Dr. Mubarak: Performing the production and interpretation of the results.

\section{Conflict of interest}

The authors disclose no any financial and personal relationships with other people or organizations that inappropriately influence (bias) our work.

\section{Funding}

Self-funding.

\section{References}

1. Tickle C. Making digit patterns in the vertebrate limb. Nat Rev Mol Cell Biol. 2006; 7(1): 45-53. doi: 10.1038/nrm1830.

2. Kornak U, Mundlos S. Genetic disorders of the skeleton: a developmental approach. Am J Hum Genet. 2003; 73(3): 447-74. doi: 10.1086/377110.

3. Sadler TW. Langman medical embryology. 12th ed. USA: Lippincott Williams \& Wilkins; 2012. p. 151.

4. Martin P. Tissue patterning in the developing mouse limb. Int J Dev Biol. 1990; 34(3): 323-36.

5. Johnson RL, Tabin CJ. Molecular models for vertebrate limb development. Cell. 1997; 90(6): 97990.

6. Salas-Vidal E, Valencia C, Covarrubias L. Differential tissue growth and patterns of cell death in mouse 
limb autopod morphogenesis. Dev Dyn. 2001; 220(4): 295-306.doi: 10.1002/dvdy.1108.

7. Vaux DL, Haecker G, Strasser A. An evolutionary perspective on apoptosis. Cell. 1994; 76(5): 777-9.

8. Pourova J, Kottova $M$, Voprsalova $M$, et al. Reactive oxygen and nitrogen species in normal physiological processes. J Acta Physiol (Oxf). 2010; 198(1): 15-35. doi: 10.1111/j.1748-1716.2009.02039.x.

9. Mooney EK, Loh C, Gross morphologic overview of lower limb development. Medscape. 2013. https://emedicine.medscape.com/article/1291712overview

10. Mori C, Nakamura N, Kimura S, et al. Programmed cell death in the interdigital tissue of the fetal mouse limb is apoptosis with DNA fragmentation. Anat Rec. 1995; 242(1): 103-10. doi: 10.1002/ar.1092420114.

11. Hinchliffe JR, Ede DA. Limb development in the polydactylous talpid3 mutant of the fowl. J Embryol Exp Morphol. 1967; 17: 385-404.

12. Baskin DS, Widmayer MA, Sharpe MA. Quantification and calibration of images in fluorescence microscopy. Anal Biochem. 2010; 404(2): 118-26. doi: 10.1016/j.ab.2010.05.029.

13. Brambrink AM, Evers AS, Avidan MS, et al. ketamineinduced neuroapoptosis in the fetal and neonatal rhesus macaque brain. Anesthesiology. 2012; 116(2): 372-84. doi: 10.1097/ALN.0b013e318242b2cd.

14. Kim Suvarna SK, Layton C, Bancroft JD. Bancroft's theory and practice of histological techniques. 7th ed. Oxford: Churchill Livingstone Elsevier; 2013.

15. Fernández-Terán MA, Hinchliffe JR, Ros MA. Birth and death of cells in limb development: a mapping study. Dev Dyn. 2006; 235(9): 2521-37. doi: 10.1002/dvdy.20916.

16. Penaloza C, Lin L, Lockshin RA, et al. Cell death in development: Shaping the embryo. Histochem Cell Biol. 2006; 126(2): 149-58. doi: 10.1007/s00418-0060214-1.

17. Milaire J, Roze M. Hereditary and induced modifications of the normal necrotic patterns in the developing limb buds of the rat and mouse: facts and hypothesis. Arch Biol. 1983; 94: 459-90.

18. Hurle JM, Ros MA, Climent V, et al. Morphology and significance of programmed cell death in the developing limb bud of the vertebrate embryo. Microsc Res Tech. 1996; 34(3): 236-46. doi: 10.1002/(SICI)1097-0029(19960615)34:3<236::AIDJEMT6>3.0.CO;2-N.

19. Pizette S, Abate-Shen C, Niswander L. BMP controls proximodistal outgrowth, via induction of the apical ectodermal ridge, and dorsoventral patterning in the vertebrate limb. Development .2001; 128(22): 446374.

20. Zuzarte-Luis V, Montero JA, Kawakami Y, et al. Lysosomal cathepsins in embryonic programmed cell death. Dev Biol. 2007; 30191): 205-17. 10.1016/j.ydbio.2006.08.008.
21. Chautan M, Chazal G, Cecconi F, et al. Interdigital cell death can occur through a necrotic and caspaseindependent pathway. Curr Biol.1999; 9(17): 967-70.

22. Nagasaka A, Kawane $K$, Yoshida $H$, et al. Apaf-1independent programmed cell death in mouse development. Cell Death Differ. 2010; 17(6): 931-41. doi: $10.1038 /$ cdd.2009.186.

23. Fallon JF, Cameron J. Interdigital cell death during limb development of the turtle and lizard with an interpretation of evolutionary significance. J Embryol Exp Morphol. 1977; 40: 285-9.

24. Penaloza C, Lin L, Lockshin RA, et al. Cell death in development: Shaping the embryo. Histochem Cell Biol. 2006; 126: 149-58. doi: 10.1007/s00418-0060214-1.

25. Ikeda T, Kanazawa T, Otsuka S, et al. Expression of Caspase Family and Muscle- and Apoptosis-Specific Genes during Skeletal Myogenesis in Mouse Embryo. J Vet Med Sci. 2009; 71(9): 1161-8.

26. Sun X, Mariani FV, Martin GR. Functions of FGF signalling from the apical ectodermal ridge in limb development. Nature. 2002; 418(6897): 501-8.

27. Rowe DA, Cairns JM, Fallon JF. Spatial and temporal patterns of cell death in limb bud mesoderm after apical ectodermal ridge removal. Dev Biol. 1982; 93(1): 83-91.

28. Dudley AT, Ros MA, Tabin CJ. A re-examination of proximodistal patterning during vertebrate limb development. Nature. 2002; 418(6897): 539-44. doi: $10.1038 /$ nature00945.

29. Conte D, Garaffo G, Lo lacono N, et al. The apical ectodermal ridge of the mouse model of ectrodactyly DIx5;Dlx6-/- shows altered stratification and cell polarity, which are restored by exogenous Wnt5a ligand. Hum Mol Genet. 2016; 25(4): 740-54. doi: 10.1093/hmg/ddv514.

30. Bober E, Franz T, Arnold HH, et al. Pax-3 is required for the development of limb muscles: a possible role for the migration of dermomyotomal muscle progenitor cells. Development. 1994; 120(3): 603-12.

31. Summerbell D, Lewis JH, Wolpert L. Positional information in chick limb morphogenesis. Nature. 1973; 244(5417): 492-6. doi: 10.1038/244492a0.

32. Wolpert L, Tickle C, Sampford M. The effect of cell killing by $\mathrm{X}$-irradiation on pattern formation in the chick limb. J J Embryol Exp Morphol. 1979; 50: 17593.

33. Kim TK. T test as a parametric statistic. Korean J Anesthesiol. 2015; 68(6): 540-6. doi: 10.4097/kjae.2015.68.6.540.

\section{Correspondence to Duha M.L. Al-Musawi E-mail: Ameerr86@yahoo.com Received Apr. $2^{\text {nd }} 2017$ Accepted Aug. 13 2017}

